\title{
Synthesis of a ten-link tooth-lever differential roller transmission mechanism
}

\author{
Abdusalam Abdukarimov ${ }^{{ }^{*}}$, Sanjarbek Madaminov ${ }^{1}$, and Asrorbek Abdullajonov ${ }^{1}$ \\ ${ }^{1}$ Institute of Mechanics and Seismic Stability of Structures, Academy of Sciences of the Republic of \\ Uzbekistan, 100125, Tashkent, Uzbekistan
}

\begin{abstract}
This article deals with the synthesis of a ten-link tooth-lever differential transmission mechanism. The article contains an analytical review of modern scientific research on the synthesis of tooth-lever differential transmission mechanisms of roller machines with a variable center distance of the working shafts; a method for the synthesis of toothlever differential transmission mechanisms of roller machines with a variable center distance of the working shafts described on the example of a ten-link tooth-lever differential transmission mechanism; the conditions for the synthesis of the mechanism given and substantiated when this mechanism is used in a roller machine; one of its working shafts has the ability to rotate about its own axis, and the second working shaft, in addition to rotation about its own axis, has the ability to move relative to the first working shaft along a line passing through the center the axes of rotation of both working shafts; the geometric synthesis of the tooth and lever contours of the mechanism, the dynamic synthesis of the mechanism, taking into account the angles of pressure between the lever link of the lever contour of the mechanism, which allows us to determine the optimal working position of the mechanism where the angles of pressure are within acceptable limits; the graphs of changes in the angles of pressure between the links of the lever contour of the mechanism, plotted depending on its position.
\end{abstract}

\section{Introduction}

Despite the widespread use of roller machines and the numerous studies of these machines conducted in recent years [1-9], roller transmission mechanisms of roller machines with variable center-to-center distances of the working shafts are studied insufficiently [10].

A roller transmission mechanism of roller machines with a variable center distance of the working shafts, transmitting torque from one working shaft to another, must provide, among other conditions, one basic condition - to ensure the rotation of the working shafts identical in value and in direction of the linear velocities of the contact point of these shafts with the processed material, both with a constant and changing center distance of the working shafts. However, many roller machines do not meet these conditions; this ultimately leads to deterioration in the processed material quality, sometimes to their

\footnotetext{
*Cooresponding author: aabdusalam54@gmail.com
} 
damage, and to a decrease in productivity and durability of the machines $[11,12]$. This problem can be solved using tooth-lever differential transmission mechanisms (TLDTM). An analysis of the design and research on tooth-lever mechanisms shows that the authors mainly considered the synthesis of tooth-lever mechanisms, in which the periodic rotational motion of the input link was converted into a periodic rotational motion of the output link with a delay, or the periodic rotational motion of the input link was converted into a rotational motion of the output link at variable speed. The weak sides of the methods for the analysis and synthesis of tooth-lever mechanisms, especially when these mechanisms are used as roller transmission mechanisms for roll modules, were pointed out by numerous authors such as N.I. Levitsky, K.V. Frolov, V.S. Karelin and others [13-15].

The authors of this study developed [16-20] and investigated [21, 22] a transmission mechanism that prevents the above disadvantages in roller machines. The article discusses the synthesis of a tooth-lever differential transmission mechanism with a parallelogram lever contour, in which the rotational motion of the input link is converted into a synchronous rotational motion of the driven link in the opposite direction, but without change in value when the center distance between the driving and driven gearwheels changes.

\section{Methods and Results}

In Figure 1 shows the design diagram of a roller pair with a developed TLDTM.

From the kinematic and dynamic analysis of this mechanism, conducted earlier, it can be seen that in order to meet the main condition, when designing a two-roll module with the same diameters of work rollers, it is necessary [22-24]:

a) The tooth contour of the toothed-lever mechanism should consist of four gearwheels if the gears have external mesh.

b) The number of teeth of the gearwheels must be identical or pairwise identical in all wheels, two idle gears and a driven with a driving one.

c) One of the lever-type contours of the tooth-lever mechanism must be a parallelogram.

d) The second lever-type contour must be axial one.

e) The mechanism must ensure a change in the center distance of the working shafts during the technological process by the value of $W_{1}$, and during the maintenance and repair work of the roller machine by the value of $W_{2}$.

f) During the technological process, the angles of pressure between the lever links should be within the permissible range.

g) The diameters of the tip circles of the driven and driving gears must be less than the minimum diameter of the working shafts to ensure the guaranteed pitch play between the teeth tips of the gearwheels.

Let us conduct a synthesis of such a mechanism.

We assume that it is necessary to design a roller machine with the diameters of the working shafts $D_{B_{1}}$ and $D_{B_{2}}$ with a change in the center distance during operation by the value of $W_{1}$, and in the process of repair and maintenance work of the roller machine - by the value of $W_{2}$. Based on the above conditions, we can write:

$$
\begin{aligned}
& D_{B}=D_{B_{1}}=D_{B_{2}}, \\
& A D_{p \cdot \max }=D_{\theta}+W_{1}, \\
& A D_{p \cdot \min }=D_{B}
\end{aligned}
$$




$$
\begin{aligned}
& A D_{n \cdot \max }=D_{b}+W_{2} \\
& A D_{n \cdot \min }=D_{a} \\
& D_{a}=D_{a_{1}}=D_{a_{2}}, \\
& D_{a}=D_{b}-\Delta .
\end{aligned}
$$

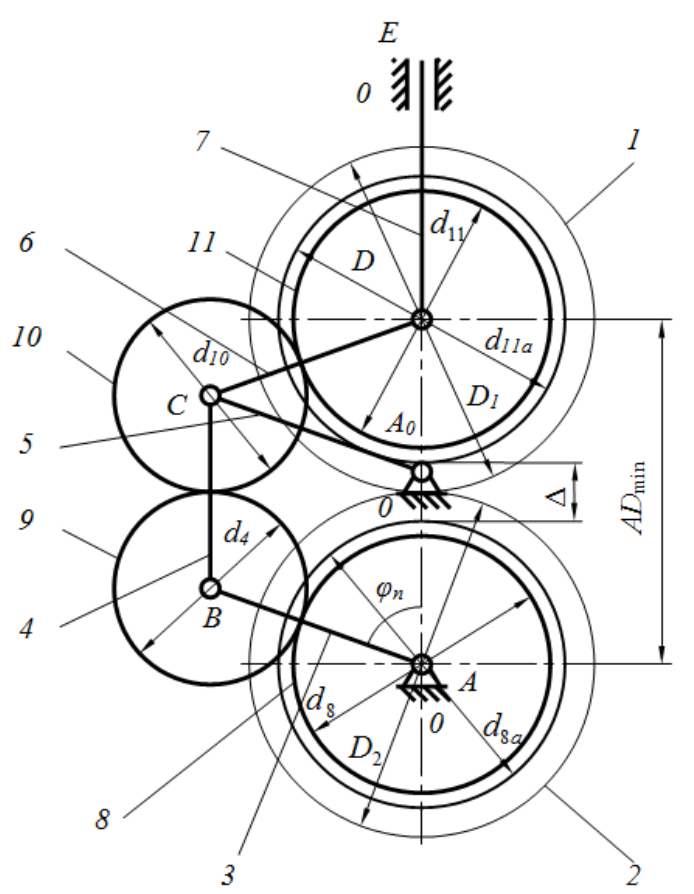

Fig.1. Diagram of a roller pair with a TLDTM: 0 - frame work; 1, 2 - working shafts; 3, 4, 5, 6, 7 levers; 8, 9, 10, 11 - gearwheels

where $D_{B_{1}}$ and $D_{B_{2}}$ are the diameters of the driving and driven working shafts, respectively; $A D_{p \text {.max }}$ and $A D_{p \text {.min }}$ are the maximum and minimum center distances of the working shafts during the technological process; $A D_{n \text { max }}$ and $A D_{n \text {.min }}$ are the maximum and minimum center distances of the working shafts during repair and maintenance work; $D_{a_{1}}$ and $D_{a_{2}}$ are the diameters of the tip circles of the driven and driving gearwheels; $\Delta$ is the guaranteed pitch play between the teeth tips of the driven and driving gearwheels.

The reference point to the teeth tips of the driving and driven gearwheels at the beginning of the design was dictated by the fact that when the center distance of the working shafts changes, the levers supporting the intermediate wheels, experience a load from the inertial force, which depends on the mass and acceleration of the centers of rotation of these gearwheels. Therefore, at a large acceleration of the change in the center distance, it is advisable to take the geometric parameters of the driving and driven gearwheels as maximum as possible, and the diameters of the intermediate gearwheels as minimum as possible in the scheme allowing to provide the value of $A D_{n \text {.мах }}$. 
With the maximum moment transmitted by the gearwheels, we determine the preliminary basic parameters of the gear transmission - the center distance of the gearwheels $\left(a_{p}\right)$, the preliminary width of the gearwheels $\left(\theta_{p}\right)$, the preliminary modulus of the tooth $\left(m_{p}\right)$, the gear ratio $(u)$, the coefficient of the width $\left(\psi_{a}\right)$, and the angle of inclination of the tooth line $(\beta)$ assuming, that the driven and driving gears are in mesh [25].

The gear ratio $u$ is determined by dividing the total gear ratio by stages. In our case $u=1$, the width factor $\left(\psi_{a}\right)$ is chosen according to the instructions given in [26].

Preliminary center distance is

$$
a_{p}=(u \pm 1) \cdot \sqrt[3]{\left(\frac{K}{\left[\sigma_{N}\right] \cdot u}\right)^{2} \cdot \frac{T_{a}^{\prime}}{\psi_{a}}}
$$

where $K=315$ for spur gear pairs; $\left[\sigma_{N}\right]$ is the permissible contact stress; $T_{a}^{\prime}$ is the estimated moment; $T_{p}^{\prime}=T_{N E} \cdot R_{N}^{\prime}=T_{\text {Max }} \cdot K_{N D} \cdot K_{N}^{\prime} ; T_{\text {Max }}$ is the greatest moment of a normally operating technological process, the opening of cylindrical gears is used where the speed of the gearwheel is less than $1 \mathrm{~m} / \mathrm{s}$.

The opening of cylindrical gears is narrow with a coefficient of width $\psi_{a}=0,1-0,2$. The coefficients of durability $K_{N D}$ and $K_{F D}$ equal to one. The "+" sign is used for external mesh, the "-" sign for internal mesh.

Then formula (8) takes the form,

$$
a_{p}=2 \cdot \sqrt[3]{\left(\frac{315}{\left[\sigma_{N}\right]}\right)^{2} \cdot \frac{T_{a}^{\prime}}{2}}
$$

in this case, the load distribution factor $K_{N \alpha}$ and the dynamic factor $K_{N D}$ included in the formula (8) are considered equal to one.

One of the features of open gears calculation is their intense wear. Therefore, they are made from normalized or heat-hardened steel. The permissible wear of open gears is up to $25 \%$ of the original thickness, in terms of the pitch circle. In this case, the bending strength is double less [26]. Therefore, the permissible stress is halved, therefore, formula (9) takes the form

$$
a_{p}=2 \sqrt[3]{\left(\frac{2 \cdot 315}{165}\right)^{2} \cdot \frac{T_{\max }}{2}}=2 \cdot \sqrt[3]{7,3 \cdot T_{\max }}=3,88 \cdot \sqrt[3]{T_{\max }}
$$

Therefore, the permissible contact stress $\left[\sigma_{H}\right]$ is determined as

$$
\left[\sigma_{N}\right]=\left[\sigma_{F}\right]=\frac{\sigma_{F \lim }^{\circ}}{S_{F}}
$$

where $\left[\sigma_{N}\right]$ is the permissible bending stress; $\left[\sigma_{F \lim }^{\circ}\right]$ is the limit of long-term endurance of the limiting gearwheel; $S_{F}$ is the safety factor.

If the life factor is $K_{N A}=1$, then the limiting gear is the driven gearwheel. 
With reversible operation, the permissible stress is multiplied by 0.8 . For Steel 40, normalized by heat treatment the following values are taken: hardness (HB 180 - 350) $\mathrm{HB}=200, \sigma_{F \lim }^{\circ}=1.8 H B ; S_{F}=1.75[11]$.

Then we obtain

$$
\begin{gathered}
\sigma_{F \lim }^{\circ}=1.8 \cdot 200=360 \mathrm{MPa} ;\left[\sigma_{H}\right]=\frac{\sigma_{F \lim }^{\circ} \cdot 0.8}{S_{F}}=\frac{360 \cdot 0.8}{1,75}=165 \mathrm{MPa}, \\
a_{p}=2 \sqrt[3]{\left(\frac{2 \cdot 315}{165}\right)^{2} \cdot \frac{T_{\max }}{2}}=3,88 \cdot \sqrt[3]{T_{\max }}
\end{gathered}
$$

Since the diameters of the teeth tips of the driven and driving gears are given, we can determine the preliminary pitch diameter of these gearwheels

$$
d_{p}=\left(D_{B}-\Delta\right)-2 m_{p}
$$

we can also determine the preliminary number of teeth

$$
Z_{p}=\frac{d_{p}}{m_{p}},
$$

The number of teeth $Z_{p}$ is rounded down to a whole number $Z$ and the preliminary module of the tooth is determined as

$$
m_{p}^{\prime}=\frac{d_{p}}{Z},
$$

from the table of modules, we take the final tooth module $(m)$.

Next, we determine the final pitch diameter

$$
d=m Z
$$

the final tooth tip diameter and final guaranteed pitch play are

$$
\begin{aligned}
& D_{a}=d+2 m, \\
& \Delta=D_{в}-D_{a} .
\end{aligned}
$$

Consider the lever contours of the TLDTM. Figure 2 shows the design scheme for the synthesis of the lever contours of the developed TLDTM.

When designing a mechanism, it is necessary to take into account a very important parameter - an angle of pressure that characterizes the condition for the transfer of forces and the operability of the mechanism. The maximum value of the angle of pressure must not exceed the permissible value, that is $v_{\max } \leq\left[v_{\text {add }}\right]$.

In the considered transmission mechanism (Figure 1), the lever part consists of two contours:

1) Rocker-slider contour;

2) Lever four-link unit (a parallelogram).

In the first contour, the leading link is slider 7, and the driven link is rocker 5 . When slider 7 moves from the driving gear, the angle of pressure in the kinematic pair $D$ is $v_{76}^{6}$ (the angle between the force $\bar{P}_{76}^{6}$ directed to link 6 from link 7 and the velocity vector $\bar{V}_{D}{ }^{6}$ directed along slider 7). When slider 7 moves to the driving gear, the angle of pressure is 
$v_{76}^{H}$ (the angle between the force $\bar{P}_{76}^{H}$ directed to link 6 from link 7 and the velocity vector $\bar{V}_{D}^{H}$ directed along slider 7). Between the links 6 and 5 in the kinematic pair $C$, the angles of pressure are $v_{64}^{B}$ and $v_{65}^{H}$, respectively. The pressure angles between links 6 and 4 in the kinematic pair $C, v_{64}^{B}$ and $v_{64}^{H}$ completely coincide with the angles of pressure between links 6 and 5.

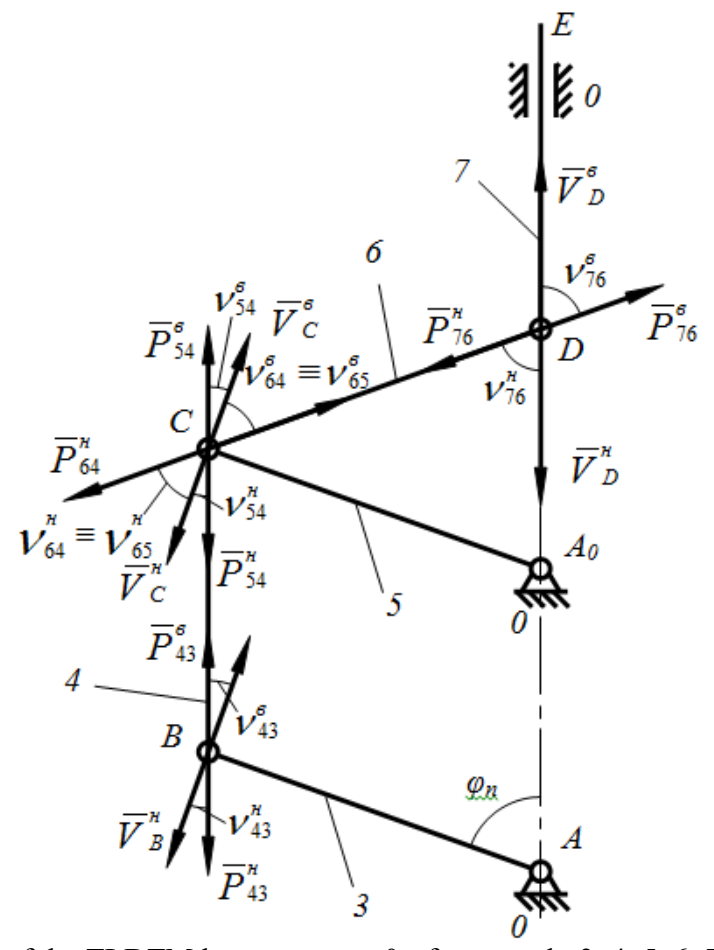

Fig.2. Design diagram of the TLDTM lever contour: 0 - framework; 3, 4, 5, 6, 7 - levers

$$
v_{64}^{B}=v_{64}^{H}=v_{64}=v_{65} .
$$

The design scheme shows that

$$
\begin{gathered}
v_{76}^{B}=v_{76}^{H}=v_{76}=\varphi_{n}, \\
v_{65}^{B}=v_{65}^{H}=v_{65}=2 \varphi_{n}-90^{\circ},
\end{gathered}
$$

we can determine the angle of position of the mechanism

$$
\varphi_{n}=\frac{v_{65}+90^{\circ}}{2} \text {. }
$$

In the second contour, the leading link is lever 5, therefore, the angles of pressure in the kinematic pair $C$ between links 5 and 4 are $v_{54}^{B}$ and $v_{54}^{H}$, and in the kinematic pair $B$ between links 4 and 3 they are $v_{43}^{B}$ and $v_{43}^{H}$. The design diagram shows that:

$$
\begin{aligned}
& v_{54}^{B}=v_{54}^{H}=v_{54}, \\
& v_{43}^{6}=v_{43}^{H}=v_{43},
\end{aligned}
$$




$$
\begin{aligned}
& v_{43}=v_{54}, \\
& v_{43}=90^{\circ}-\varphi_{n},
\end{aligned}
$$

Hence, we can write

$$
\varphi_{n}=90^{\circ}-v_{43} \text {. }
$$

Equating the right-hand sides of formulas (22) and (27), we can write

$$
v_{54}=90^{\circ}-2 v_{43} \text {. }
$$

From formulas (20), (22), (27) it is seen that an increase in angle $\varphi_{n}$ leads, on the one hand, to a decrease in pressure angle $v_{43}$, and, on the other hand, to an increase in pressure angles $v_{65}$ and $v_{76}$. In preliminary calculations, the mechanisms with rotational pairs only $[v]=45^{\circ}-60^{\circ}$ are considered, in the presence of translational kinematic pairs $[v]=30^{\circ}-45^{\circ}$, therefore,

$$
\begin{aligned}
& {\left[v_{76}\right]=45^{\circ}-60^{\circ},} \\
& {\left[v_{65}\right]=30^{\circ}-45^{\circ},} \\
& {\left[v_{43}\right]=30^{\circ}-45^{\circ} .}
\end{aligned}
$$

Formulas (20), (21), and (26) satisfy conditions (29), (30), and (31) at $\varphi_{n}=45^{\circ}-30^{\circ}$.

Figure 3 shows graphs of changes in the angles of pressure $v_{43}, v_{54}, v_{64}, v_{65}, v_{76}$ depending on the angle of position $\varphi_{n}$ of the mechanism. The actual change in the angle of position $\varphi_{n}$ of the mechanism should be less than $15^{\circ}\left(45^{\circ}-30^{\circ}\right)$. It should be noted that the value of the permissible pressure angles $\left[v_{65}\right]=\left[v_{64}\right]$ can be in the range from $\left(-45^{\circ}\right) \div\left(-30^{\circ}\right)$ to $\left(+30^{\circ}\right) \div\left(+45^{\circ}\right)$, which corresponds to the angle of position from $22,5^{\circ}$ to $67,5^{\circ}$ according to the formula (22).

Let us proceed to the determination of the pitch radius $\left(r_{n}\right)$ of the intermediate wheel at the angle of position of the mechanism $\varphi_{n}=45^{\circ}$ and the value of the minimum angle of position of the mechanism $\left(\varphi_{n \text {.min }}\right)$ that satisfy the condition for changing the center distance in the working position $\left(W_{1}\right)$.

From the design scheme (Fig. 1) we can write

$$
\begin{gathered}
A D_{p \cdot \min }=2\left(r+r_{n}\right) \cos \varphi_{n \cdot \max }+2 r_{n}, \\
A D_{p \cdot \max }=2\left(r+r_{n}\right) \cos \varphi_{n \cdot \min }+2 r_{n}, \\
A D_{p \cdot \min }=d+\Delta, \\
A D_{p \cdot \max }-A D_{p \cdot \min }=W_{1},
\end{gathered}
$$

where $r$ is the pitch radius of the driving and driven gears.

From formula (32), taking into account formulas (33), (34), (35), we obtain

$$
r_{n}=\frac{d+\Delta-r \sqrt{2}}{2+\sqrt{2}}
$$


where $r_{n}$ is the pitch radius of the intermediate wheels, which ensures $D_{a}+\Delta=A D_{p \cdot \min }$ at the angle of position of the mechanism $\varphi_{n}=45^{\circ}$.

Subtracting formula (32) from formula (33) and taking into account formulas (35) and (36), we can write

$$
\varphi_{n, \min }=\arccos \left(\frac{W_{1}(2+\sqrt{2})+\sqrt{2}(2 d+\Delta)}{2(2 d+\Delta)}\right)
$$

Substituting the given value of $W_{1}$ and the value $d$ from the formula (11) into the formula (37), $\varphi_{n \text {.min }}$ is determined. If $\varphi_{n \text {.min }} \geq\left[\varphi_{n \text {.min }}=30^{\circ}\right]$, then we make further calculations, if $\varphi_{n \cdot \min }<\left[\varphi_{n \cdot \min }=30^{\circ}\right]$, then, increasing $Z_{n}$ by one tooth, we redetermine $\varphi_{n \text {.min }}$, until the condition $\varphi_{n \text {.min }} \geq\left[\varphi_{n \text {.min }}=30^{\circ}\right]$ is met.

After satisfying the condition, accepting the resulting $Z_{n}$, we determine the final pitch diameter of the intermediate wheels

$$
d_{n}=Z_{n} \cdot m
$$

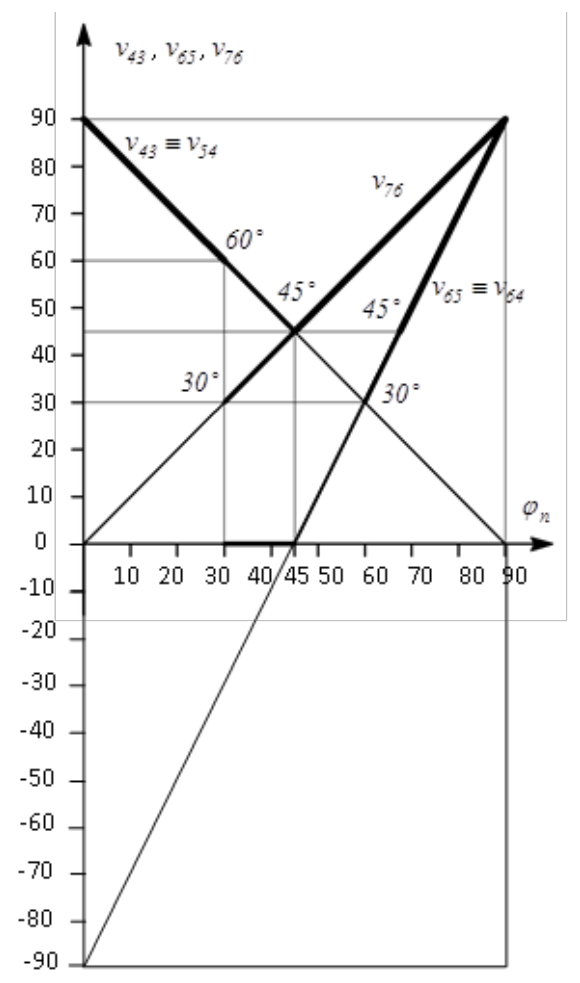

Fig. 3. Graphs of changes in angles of pressure $v_{43}, v_{54}, v_{64}, v_{65}, v_{76}$, depending on the angle of the position $\varphi_{n}$ of the mechanism

Next, we determine the length of the arms and the maximum value of the roller distance 


$$
\begin{aligned}
& l_{A B}=l_{C D}=\frac{d+d_{n}}{2}, \\
& l_{C B}=l_{A A_{o}}=d_{n}, \\
& A D_{n \text {. } \max }=D_{s}+W_{2}, \\
& W_{2}=d+2 d_{n}-D .
\end{aligned}
$$

In the design of a transmission mechanism for roller machines with a low acceleration of the center of rotation of the driven working shaft, it is advisable to take the pitch diameters of all gearwheels equal to $d=d_{n}$, considering the geometric parameters of the roller pair and the technological requirements, which is rational from economic and operational points of view.

\section{Conclusions}

a) An A method of geometric and dynamic synthesis of a tooth-lever differential transmission mechanism with a parallelogram lever contour was developed, applied to tworoll modules with a variable center distance of the working shafts when the center of rotation of one of the working shafts moves along a straight line passing the centers of rotation of the roller pairs.

b) Formulas were derived for determining the angle of position of the mechanism, depending on the angles of pressure; the values of the angles of position of the links corresponding to the permissible values of the angles of pressure were determined.

c) Formulas were derived for determining the geometric parameters of the transmission mechanism, depending on the geometric parameters of a two-roll module and the technological requirement for the module, expressed by the value of the maximum change in the inter-roller distance during the technological process and during repair and maintenance work; and depending on the torque transferred by gearwheels, taking into account dynamic factors of rational angles of pressure of lever contours.

\section{References}

1. G. Bahadirov, G. Tsoy, A. Nabiev, Study of the efficiency of squeezing moisturesaturated products, EUREKA: Physics and Engineering 1, 86-96 (2021)

2. A.T. Amanov, G.A. Bahadirov, G.N. Tsoy, A.M. Nabiev, A New Method to Wring Water-Saturated Fibrous Materials International Journal of Mechanical Engineering and Robotics Research 10(39), 151-156 (2021)

3. T.M. Mavlonov, A.B. Akhmedov, R.Kh. Saidakhmedov, K.G. Bakhadirov, Simulation modeling of cold rolled metal strip by asymmetric technology, IOP Conf. Ser.: Mater. Sci. Eng. 883012194 (2019)

4. G. Bahadirov, G. Tsoy, A. Nabiev, Study of the efficiency of squeezing moisturesaturated products EUREKA: Physics and Engineering 1, 86-96 (2021)

5. Y.X. Liu, S.L. Zou, T. Tang, Q.W. Zhou, Study on Simulation of the Chain Transmission Mechanism, Advanced Materials Research 591-593, 797-800 (2012)

6. R. Saydakhmedov, K. Bakhadirov, Crystallographic structural changes of Al1050 under different types of sheet metal rolling, E3S Web Conf. 264, 05010 (2021)

7. Sh.R. Khurramov, Simulation of the form of contact curves rolls in two-roll modules, IOP Conf. Series: Earth and Environmental Science 614012096 (2020) 
8. Sh.R. Khurramov, Some questions of the contact interaction theory in two-roll modules, Journal of Physics: Conf. Series 1546, 012132 (2020)

9. W. Jia, L. Ma, M. Jiao, Q. Le, T. Han, Ch. Che, Fracture criterion for predicting edgecracking in Hot rolling of twin-roll casted AZ31 Mg alloy, J. Materials Research and Technology 9, 4773-4797 (2020)

10. Sh.R. Khurramov, Modeling of Friction Stress in Twin Roll Modules, Journal of Physics: Conference Series 1789, 012004 (2021)

11. T. Hänninen, A. Thygesen, Sh. Mehmood, B. Madsen, M. Hughes, Mechanical processing of bast fibres: The occurrence of damage and its effect on fibre structure, Industrial Crops and Products 39, 7-11 (2012)

12. P. Thanikaivelan, J.R. Rao, B.U. Nair, Th. Ramasami, Recent Trends in Leather Making: Processes, Problems, and Pathways, Critical Reviews in Environmental Science and Technology 35(1), 37-79 (2005)

13. M.Z. Kolovsky, A.N. Evgrafov, Y.A. Semenov, A.V. Slousch, Advanced Theory of Mechanisms and Machines, Springer-Verlag, Berlin, Germany (2000)

14. A.S. Mata, B.A. Torras, C.J.A. Carrillo, E.F. Juanco, G.A.J. Fernández, N.F. Martínez, O.A. Fernández, Fundamentals of Machine Theory and Mechanisms, Springer, Switzerland (2016)

15. K.B. Ganti, Analysis and Design of a Gear Shifting Mechanism for Transmission Based Actuators, Master's Thesis, University of Tennessee, Tennessee (2003)

16. A. Abdukarimov, G.A. Bahadirov, Sh.R. Khurramov, A.A. Abdukarimov, S.M. Madaminov, Patent for invention RUz № FAP 01447 Universal roller machine Official Bulletin №12 (2019)

17. A. Abdukarimov, G.A. Bahadirov, I. Kh. Saidokulov, A. A. Abdukarimov, Patent for invention RUz № FAP 01446 Gear-link differential transmission mechanis Official Bulletin №12 (2019)

18. A. Abdukarimov, G.A. Bahadirov, Sh.R. Khurramov, SH.T. Ravutov, I.Kh. Saidokulov, N.B. Saydakhmetova, A.P. Urinov, A.A. Abdukarimov, Patent for invention RUz № IAP 06400 Differential gear mechanism Official Bulletin №1 (2021)

19. A. Abdukarimov, G.A. Bahadirov, S.M. Madaminov, Patent for invention RUz №. FAP 01542. Tooth-lever differential transmission mechanism Official Bulletin №10 (2020)

20. G.A. Bahadirov, A. Abdukarimov, Sh. R. Khurramov, A. M. Nabiev, A. A. Umarov, Patent for invention RUz № IAP 05886 Device for removing moisture from wet fibrous materials Official Bulletin №7 (2019)

21. T.Yu. Amanov, A. Abdukarimov, G.A. Bahadirov, Patent for invention 1632047 A1 USSR, Transmission mechanism of the roller machines, MKI C14 B 1/00, 1/02.

22. A. Abdukarimov, et al. Force analysis of the transmission mechanism of a roller pair of a squeezing machine, Scientific and Technical Journal FerPI, 4, 31-35 (2019)

23. A. Abdukarimov, Analysis and synthesis of transmission mechanisms of roller machines with variable center distance of the working shafts, Dis. Cand. Tech. Sci., IMSS, Tashkent (1995).

24. A. Abdukarimov, G.A. Bahadirov, Analysis of the gear-lever differential transmission mechanism of roller machines with variable center distance of the working shafts, International Conference on Progressive Technologies and Systems of Mechanical Engineering, Donetsk National Technical University, 1.2(44), 3-9 (2012)

25. T.G. Hicks, Handbook of Mechanical Engineering Calculations, Second Edition, McGraw-Hill Education: New York, Chicago, San Francisco, Athens, London, Madrid, Mexico City, Milan, New Delhi, Singapore, Sydney, Toronto (2006, 1998)

26. M.A. Gonza'lez-Palacios, J. Angeles, The Design of a Novel Mechanical Transmission for Speed Reduction, ASME. J.Mech. Des. 121(4), 538-543 (1999) 